\title{
The TOBg Tobacco Treatment Guidelines for Adolescents: A real-world pilot study
}

\author{
Anastasios Fotiou, ${ }^{1}$, Myrto Stavrou ${ }^{1}$, Sophia Papadakis ${ }^{2,3}$, Panagiotis K. Behrakis, ${ }^{4,5}$, Constantine I. Vardavas ${ }^{5,4}$, \\ Maria Kyriakidou ${ }^{6}$, Sotiria Makaroni7, Theodosia Peleki ${ }^{5,4}$, Vergina Vyzikidou ${ }^{5,4}$, Anna Kokkevil,8
}

\section{ABSTRACT}

INTRODUCTION We conducted a pilot study to: 1) obtain feedback from prevention practitioners in terms of their satisfaction, knowledge, and self-efficacy following exposure to the Tobacco Treatment Guidelines for Adolescents (TOBg Guidelines); and 2) examine the effectiveness of a school-based intervention based on the TOBg Guidelines on quit rates among a sample of adolescent tobacco users.

METHODS Two parallel studies were conducted. In Study 1, prevention practitioners were exposed to a 1-day training in the TOBg Guidelines with assessment occurring before, immediately after, and at 6 months following the training. In Study 2, participating adolescent smokers were exposed to a 3-session group-based smoking cessation intervention that drew on the TOBg Guidelines and was delivered by practitioners trained in Study 1. The primary outcome measure was self-reported smoking status assessed at 1 month and at 6 months following baseline.

RESULTS A total of 18 prevention practitioners and 65 adolescent tobacco users participated in the pilot study. The majority of practitioners reported high rates of satisfaction with the $\mathrm{TOBg}$ Guidelines and indicated that the guidelines positively influenced the manner in which they addressed tobacco use with adolescents. Prevention practitioners' self-efficacy for intervening with adolescent smokers was also significantly increased following exposure to the TOBg Guidelines and training. Among adolescents exposed to the school-based intervention, $62.5 \%$ and $23.1 \%$ had reduced smoking by $50 \%$ or more at 1 month and at 6 months follow-up, respectively. No significant change in smoking abstinence was documented.

CONCLUSIONS The TOBg Guidelines for adolescent smokers were well received by prevention practitioners and were feasible to implement in a real-world school setting.

\author{
AFFILIATION \\ 1 University Mental Health \\ Research Institute (UMHRI), \\ Athens, Greece \\ 2 Division of Prevention and \\ Rehabilitation, University of \\ Ottawa Heart Institute, Ottawa, \\ Canada \\ 3 Faculty of Medicine, University \\ of Ottawa, Ottawa, Canada \\ 4 George D. Behrakis Research \\ Lab, Hellenic Cancer Society, \\ Athens, Greece \\ 5 Institute of Public Health, \\ American College of Greece, \\ Athens, Greece \\ 6 PYXIDA Prevention Centre, \\ Thessaloniki, Greece \\ 7 PRONOI Prevention Centre, \\ Athens, Greece \\ 8 Department of Psychiatry, \\ National and Kapodistrian \\ University of Athens, Medical \\ School, Athens, Greece
}

CORRESPONDENCE TO University Mental Health Research Institute (UMHRI), 2, Soranou tou Efesiou str., P.O. Box 665 17, Papagou, GR-156 01 Athens, Greece. E-mail: afotiou@med.uoa.gr

\section{KEYWORDS}

adolescents, pilot study, tobacco cessation, schoolbased intervention

Received: 26 March 2018 Revised: 15 June 2018 Accepted: 6 July 2018

\section{INTRODUCTION}

An estimated $21 \%$ of 16-year-old students in Europe are current smokers and $13 \%$ report daily smoking ${ }^{1}$. Nicotine dependence develops quickly during adolescence and a large proportion of adolescents who smoke regularly will continue smoking during adulthood ${ }^{2-4}$. As with other health behaviours and addictions (e.g. alcohol, drug use, unsafe sexual practices, etc. $)^{5}$, the early identification and treatment of adolescent tobacco use is important for 
preventing more serious short- or long-term health consequences ${ }^{6}$.

Adolescent tobacco users are recognized as a special population that requires tailored interventions for smoking cessation. Interventions targeting adolescent smokers have increased in number in recent years ${ }^{7,8}$. However, the lack of robust and adequately powered randomized controlled trials, coupled with complete reliance on models originally designed for adults, has limited and confounded the evidence regarding the efficacy of available interventions in supporting cessation among adolescents ${ }^{7-10}$. A 2017 Cochrane systematic review identified group-based behavioural interventions as the most promising approach, supporting the findings of an earlier metaanalysis of 48 trials involving adolescent smokers, which concluded that tobacco cessation programs are more likely to be effective if they are offered within the school setting ${ }^{10}$. Specifically, motivational enhancement intervention programs that are delivered in schools over an extended period, and which include multiple components, have been found to be the most effective approach for prevention of smoking initiation ${ }^{11}$, short-term smoking cessation and smoking reduction ${ }^{8}$.

The 2017 Tobacco Cessation Guidelines for High-risk Groups (TOBg Guidelines) ${ }^{12}$ were produced with the aim to develop and implement an innovative and cost-effective approach for the prevention of chronic diseases related to tobacco dependence by developing specialized tobacco cessation guidelines for high-risk populations. The TOBg Guidelines include a special chapter on tobacco treatment among adolescent tobacco users designed to assist both health and prevention practitioners in delivering evidence-based tobacco cessation interventions for adolescent smokers in various settings, with a special focus on interventions delivered in schools. The Guidelines are available online at http://TOB.g.eu/.

We conducted a pilot study to: 1) obtain feedback from prevention practitioners in terms of their satisfaction, knowledge and self-efficacy following exposure to the Tobacco Treatment Guidelines for Adolescents (TOBg Guidelines) and 2) examine the effectiveness of a school-based intervention, implementing the $\mathrm{TOBg}$ Guidelines on quit rates, among a sample of adolescent tobacco users.

\section{METHODS}

The pilot study consisted of two parallel studies.

\section{Design of Study 1 - Testing TOBg Guidelines among prevention practitioners}

In Study 1, we conducted a pre-post evaluation to examine the impact of the TOBg Guidelines and training program on prevention practitioners' level of knowledge, expressed level of satisfaction with the guidelines, and reported the impact on their self-efficacy. Measurements took place before, immediately after, and at 6 months following exposure to the 1-day training program.

\section{Participants of Study 1}

Participants in the training program consisted of prevention practitioners employed in specialised Centres for the Prevention of Substance Use and the Promotion of Psychosocial Health in Greece (hereinafter 'Prevention Centres'). In Greece, prevention practitioners have responsibility for the design and implementation of health-promoting/ risk-averting interventions in schools and the community. The Prevention Centres are located in the major city of each prefecture of the country and are funded by the government. Their services cover several health-risk behaviours, including tobacco and other substance use, aggression and bullying. Prevention practitioners work directly with adolescents, both within and outside the school-setting, and they are thus presented with an opportunity to identify and intervene with adolescent smokers.

An invitation letter was sent to the administrators of all 75 Prevention Centres in operation in Greece in 2017. Thirteen Prevention Centres expressed their interest to participate in the study, delegating to the pilot study a total of 18 practitioners. Eligibility criteria set for the participation of practitioners in the study were: 1) be experienced in designing and implementing school-based interventions, 2 ) be experienced with working directly with adolescent students, 3) be available to participate in the TOBg Guidelines training session, and 4) have good knowledge of the English language (the TOBg Guidelines were available only in English). Current and past smoking status of the prevention practitioners were not among the eligibility criteria. 


\section{Procedure of Study 1}

A 1-day training session was conducted in Athens, Greece, in March 2017. Participating practitioners received an electronic or hard copy of the TOBg Guidelines before the training. During the training, experts involved in the co-authorship of the guidelines presented and discussed evidence-based key recommendations pertaining to tobacco cessation among adolescent smokers. Training also included practical guidance for the implementation of a groupbased smoking cessation intervention for school settings to assist students who smoke with quitting. Practitioners completed the TOBg provider survey, which measured their demographic and smoking characteristics, tobacco cessation knowledge and self-efficacy immediately before the training session (Time $1-\mathrm{T} 1$ ) and at the end of the training day (Time $2-\mathrm{T} 2$ ), in order to measure the immediate impact of the training session on their level of knowledge and their perception of self-efficacy. A follow-up survey (by e-mail) was conducted at 6 months following training (Time 3 T3) to assess the prevention practitioners' satisfaction, and their perception of self-efficacy, in developing smoking cessation interventions based on the TOBg Guidelines. Two email reminders were sent, at 7 and 14 days following the first contact, to those who had not responded. A phone call was made to anyone who had not responded to the reminders. All participants provided data at the post-training assessment at the 1 month follow-up, but only $89 \%$ provided data at the 6 months follow-up assessment (Figure 1).

Figure 1: Flow diagram for Study 1: Number of prevention centres and prevention practitioners who participated in the study

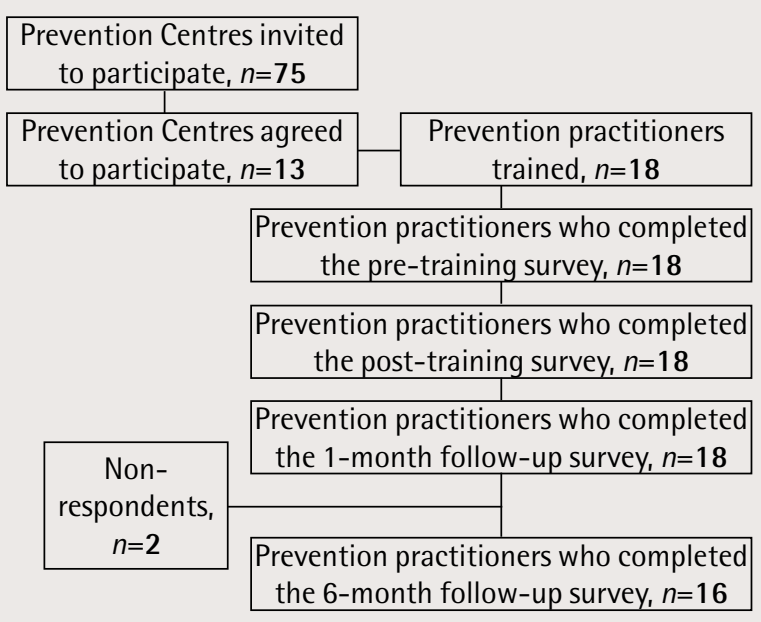

\section{Outcome measures and instruments of Study 1}

Six areas of satisfaction were assessed: 1) assessment of practitioners' overall satisfaction with the guidelines; 2) the appropriateness of guideline length, 3) ease of understanding, 4) extent to which new information was provided, 5) extent of missing information, and 6) perceived impact of the guidelines on the approach with which they address tobacco use with adolescents. Practitioners' knowledge was assessed with the use of a 10-item questionnaire that was based on the information presented in the adolescents section of the TOBg Guidelines ${ }^{8}$. Practitioners' perception of self-efficacy in delivering smoking cessation interventions was assessed using a 6-item questionnaire allowing responses on a 10-point rating scale; with 1 indicating lack of confidence and 10 - extreme confidence. This has been adapted from previously published instruments ${ }^{13-16}$.

\section{Design of Study 2 - Group-based smoking cessation intervention for adolescents}

Study 2 examined the effectiveness of a pilot smoking cessation intervention that drew on the TOBg Guidelines and was delivered in a sample of highschools in Greece. The primary outcome measure was adolescent smoking status assessed at baseline, at 1 month and at 6 months. Secondary outcome measures included reduction in student's daily smoking consumption.

\section{Participants of Study 2}

Student eligibility criteria for the study included: 1) weekly tobacco use, 2) interest in quitting smoking in the next 30 days, 3 ) being between the ages of 13 and 19 years, 4) willing to complete the study survey, and 5 ) have access to a telephone for follow-up. Eligible students were sought from within a convenience sample of 20 schools, the head-teachers of which responded positively to the invitation of the local practitioners. A total of 783 students participated in the initial information session, irrespective of their smoking status. Among them, 115 smokers accepted to be screened for eligibility. Following screening, nine students were deemed ineligible as they either were over the age of 19 years $(n=6)$ or smoked less than weekly $(n=3)$. Among eligible students $(n=106), 41$ students did not participate 
in the main phase of the intervention. Reasons for non-participation included: expressed concerns that their parents and/or teachers would find out that they smoke (especially given the required parental consent), hesitations to make the time commitment for the whole duration of the intervention and the "not convenient' timing of the intervention (close to final school exams). Finally, 65 eligible students agreed to participate in the main phase of the intervention. The recruitment flow diagram is presented in Figure 2.

Figure 2: Flow diagram for Study 2: Number of students aged 13-19 who participated to the pilot intervention

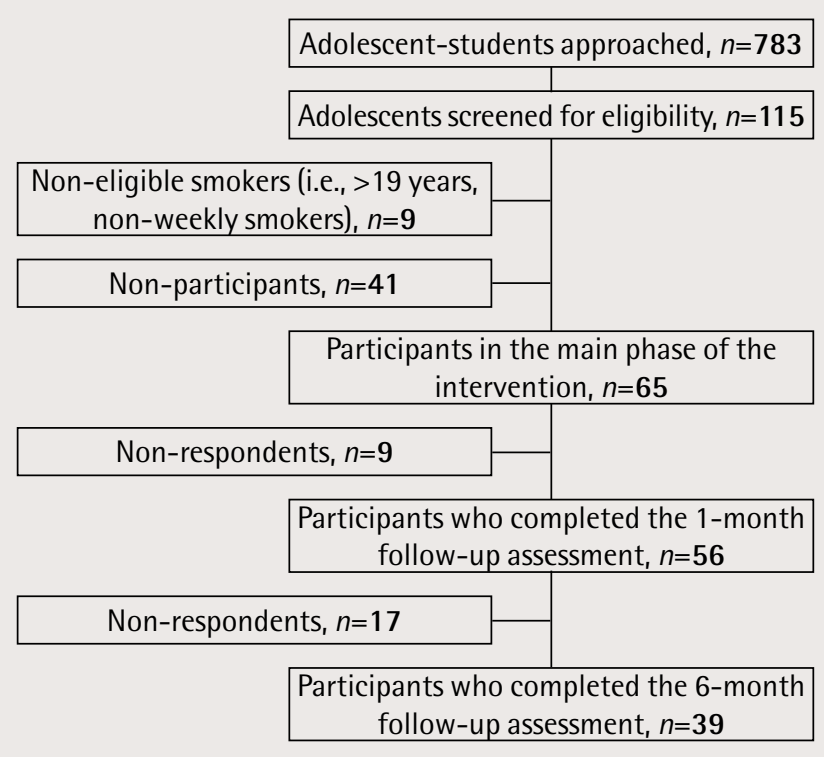

\section{Procedure of Study 2 - Intervention}

Prevention practitioners, who were trained in the TOBg Guidelines (Study 1), approached one highschool under their area of responsibility and delivered a 2-hour information session addressed to all students, smokers and non-smokers (baseline). The session provided information about the benefits of abstaining from smoking. At the end of the session, adolescents were invited to fill-in an anonymized survey assessing demographic characteristics and smoking related history. Practitioners screened student surveys and invited eligible adolescent smokers to join a groupbased cessation program offered at their school in the weeks immediately following the baseline session. Drawing on the evidence-based recommendations included in the TOBg Guidelines ${ }^{8}$, the program comprised three 2-hour group sessions based on motivational enhancement and cognitive-behavioural techniques, as well as the provision of self-help material. A paper-based follow-up survey assessing their smoking status was conducted at 1 month $( \pm 2$ weeks) and a telephone-based survey at 6 months $( \pm$ 2 weeks) following baseline.

\section{Outcome measures and instruments}

The primary outcome measure was the self-reported point prevalence of smoking abstinence assessed at 1 month and at 6 months follow-up, according to the Russell Standard ${ }^{17}$. A secondary outcome measure was the proportion of students reporting a reduction by at least $50 \%$ in cigarettes smoked per day (CPD). The study also considered the proportion of students reporting a reduction of 2 or more CPD at follow-up. For any adolescents with missing data we assumed that they had returned to active smoking, according to the Russell Standard ${ }^{17}$.

\section{Ethics procedures}

Prevention practitioners provided individual written informed consent. Eligible students and their parents/guardians provided written informed consent. This study was approved by the ethical committee of the Athens University Mental Health Research Institute (UMHRI).

\section{Analysis}

Descriptive analysis was used to summarize the demographic characteristics of Study 1 and Study 2 participants. Pearson's chi-squared statistics were used to examine categorical data and paired samples t-tests for continuous data. The significance level was set at a $=0.05$. IBM SPSS Statistics for Windows, Version 24.0 (Armonk, NY: IBM Corp.) was used to analyse all data.

\section{RESULTS}

\section{Results of Study 1 - Testing TOBg Guidelines among prevention practitioners}

\section{Participant characteristics}

Demographic and educational characteristics of the prevention practitioners are presented in Table 1. The majority were female (88.9\%), psychologists, with mean age of $41.4 \pm 6.1$ years standard deviation (SD). Based on self-reports, $11.8 \%$ of the practitioners were current smokers, $41.2 \%$ were past smokers and $47.0 \%$ had never smoked. 
Table 1. Descriptive characteristics of prevention practitioners who participated in the TOBg training for adolescents $(n=18)$

$\begin{array}{lc}\text { Varialble } & \text { Valuce } \\ \text { Gender, \% } & \\ \text { Female } & 88.9 \\ \text { Male } & 11.1 \\ \text { Age (years), mean (SD) } & 41.4(6.1) \\ \text { Educational/professional background, \% } & \\ \text { Psychologist } & 61.1 \\ \text { Social worker } & 27.8 \\ \text { Other } & 11.1 \\ \text { SD: standard deviation } & \end{array}$

\section{Satisfaction, knowledge, and self-efficacy}

Table 2 presents the results of prevention practitioners' satisfaction with the Guidelines. The majority of the practitioners $(76.9 \%)$ reported that they were 'extremely satisfied' with the TOBg Guidelines for adolescents and that they considered them easy to understand. However, almost 1 in 4 $(23.1 \%)$ reported that the guidelines were missing information and $15.4 \%$ that they were too long. The majority of practitioners indicated that the guidelines will influence the manner in which they intervene with adolescents who smoke. While the majority of practitioners agreed ('very much') that the guidelines offered new information, $30.8 \%$ of the total sample reported that this was only 'somewhat' true.

Table 3 presents a summary of the percentage of
Table 2. Level of satisfaction and perceived utility of the TOBg Guidelines among prevention practitioners at the 6 month follow-up assessment $(n=13)$

\begin{tabular}{lr} 
Qurestion & \\
How satisfied are you with the TOBg Guidelines as a whole? & \\
Not satisfied at all & 0.0 \\
Somewhat satisfied & 0.0 \\
Satisfied & 15.4 \\
Very satisfied & 7.7 \\
Extremely satisfied & 76.9 \\
Was the Guidelines' length appropriate? & \\
A little too short & 7.7 \\
An appropriate length & 76.9 \\
A little too long & 15.4 \\
Very long & 0.0 \\
Was there information missing from the Guidelines? & \\
No & 76.9 \\
Yes & 23.1 \\
Was the Guidelines document easy to understand? & \\
Not easy at all & 0.0 \\
Very difficult & 15.4 \\
Easy & 7.7 \\
Very easy & 61.5 \\
Extremely easy & 15.4 \\
Did the Guidelines provide you with new information & \\
on tobacco treatment? & \\
Not at all & \\
Somewhat & \\
Very much & \\
Will the Guidelines influence the manner in which you & \\
address tobacco use with adolescents who smoke? & \\
Not at all & 6.0 \\
To some extent & 15.4 \\
To a great extent & \\
\hline & \\
\hline
\end{tabular}

Table 3. Difference in the percentage (\%) of correct responses of prevention professionals regarding tobacco treatment knowledge before and after the TOBg training program (correct answers in italics)

\section{Knowledge question}

A greater proportion of adolescents smoke in Europe compared to the United States. True

Most adolescent tobacco users do not consider themselves addicted. True

When speaking to adolescents about quitting smoking one should emphasize ... Both its shortand long-term health benefits

The best practices for helping adolescents quit smoking are the same as for the adult population. False Which of the following smoking cessation medications are safe to use in adolescent populations? Nicotine replacement therapy

What is the recommended practice in terms of the use of nicotine replacement therapies (NRT) among the adolescent population? Limited evidence available; it is up to the physician and/or the guardians to decide about their benefit

How long does a craving typically last? 3-5 minutes

When working with adolescents, evidence suggests the following strategies are most effective in reducing tobacco use... Counseling based on the combination of motivational enhancement and behavioral approaches The school setting is an effective setting for delivering smoking cessation interventions. True Length of intervention is an important predictor in successful or at least promising smoking cessation outcomes. True

$\begin{array}{rrc}\text { Pre }(T 1), \% & \text { Post (T2), } \% & \\ n=18 & n=16 & p \\ 72.2 & 66.7 & 0.062 \\ 94.4 & 77.8 & 0.222 \\ & & \\ 58.8 & 50.0 & 0.618 \\ 77.8 & 94.1 & 0.784 \\ & & \\ 87.5 & 61.1 & 0.649 \\ & & \\ 56.3 & 55.6 & 0.159 \\ 88.8 & 77.8 & 0.142 \\ 94.4 & 77.8 & 0.803 \\ 100.0 & 100.0 & 1.0 \\ 94.4 & 100.0 & 0.809\end{array}$


Table 4. Prevention practitioners' perceived self-efficacy related to the delivery of evidence-based smoking cessation interventions before and after the TOBg training program

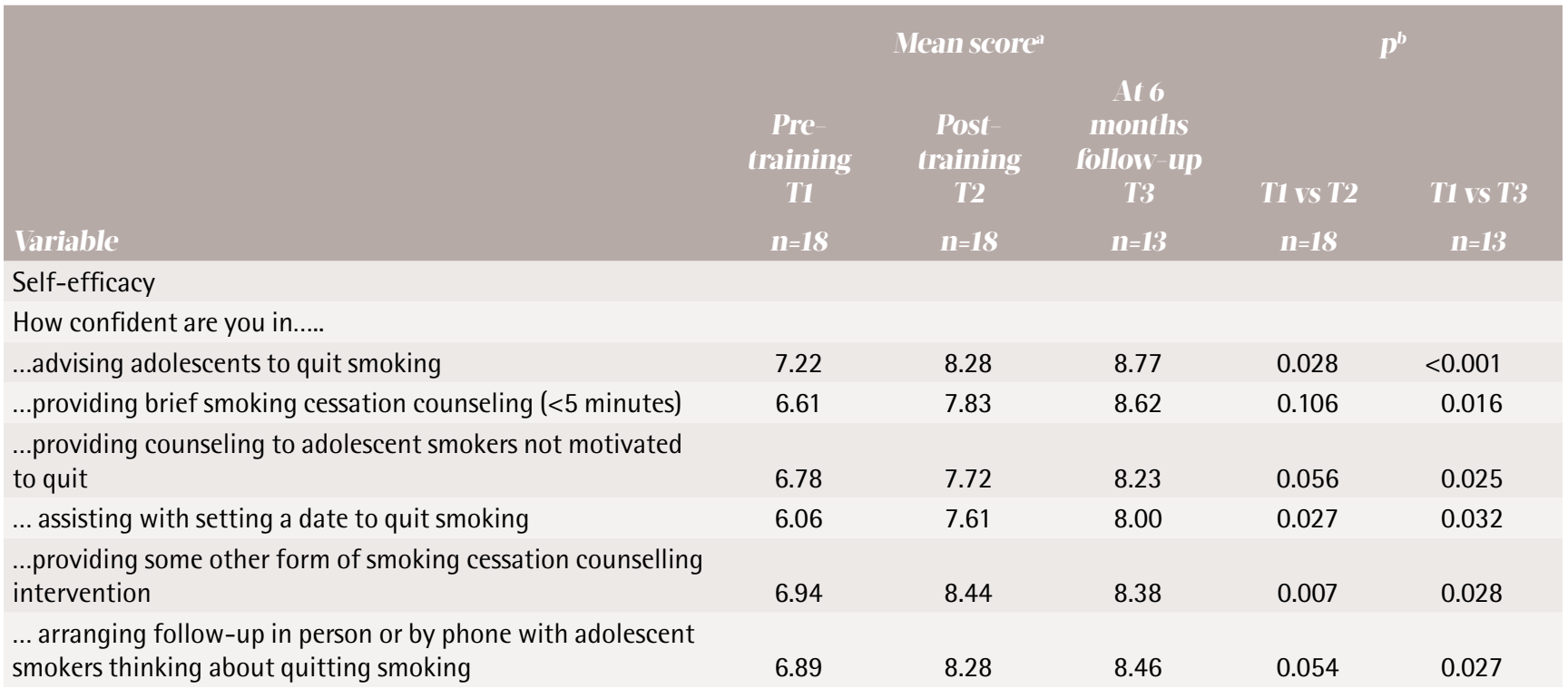

a Responses reported on a scale of 1 to $10 ; 1$ being 'not all confident' and 10 being 'extremely confident'.

b Only those practitioners with data at both the pre (T1) and post $(\mathrm{T} 2, \mathrm{~T} 3)$ assessments were included in the analysis.

Table 5. Characteristics of adolescent smoker participants $(n=65)$

$\begin{array}{lc}\text { Varialble } & \text { II (\%) } \\ \text { Gender } & \\ \text { Male } & 36(58.1) \\ \text { Female } & 26(41.9) \\ \text { Age (Years) } & \\ 15 & 1(1.5) \\ 16 & 11(16.9) \\ 17 & 37(56.9) \\ 18 & 11(16.9) \\ 19 & 5(7.7) \\ \text { Frequency of smoking } & \\ \text { Daily } & 52(80.0) \\ \text { Weekly } & 6(9.2) \\ \text { Missing } & 7(10.8) \\ \text { Cigarettes/day } & \\ 1-5 & 7(10.8) \\ 6-10 & 20(30.8) \\ 11-19 & 12(18.5) \\ 20 \text { or more } & 19(29.2) \\ \text { Missing } & 7(10.8) \\ \text { Time to first cigarette immediately after waking up } & \\ \text { Within } 5 \text { minutes } & 16(24.6) \\ 6-30 \text { minutes } & 13(20.0) \\ 31-60 \text { minutes } & 8(12.3) \\ \text { After } 60 \text { minutes } & 21(32.3) \\ \text { Missing } & 7(10.8) \\ \text { Friends who smoke } & \\ \text { A few } & 2(3.1) \\ \text { Most of them } & 37(56.9) \\ \text { All of them } & 19(29.2) \\ \text { Missing } & 7(10.83)\end{array}$

prevention practitioners who responded correctly to the knowledge questions. While there were positive changes observed in some of the knowledge assessment questions, no statistically significant changes were observed. In two cases, there was a decrease in correct responses following the training.

There was a significant increase in the perceived self-efficacy of practitioners regarding the delivery of evidence-based treatments for tobacco use following the training in all six areas assessed at the 1 month and 6 months follow-up (Table 4).

\section{Results of Study 2 - Group-based cessation intervention for adolescents}

Participant characteristics

Table 5 summarizes the demographic characteristics of student participants. Participants (41.9\% females) had a mean age of 17.1 (SD: \pm 0.84 ) years. At baseline, $80.0 \%$ of tobacco users reported smoking daily and $9.2 \%$ reported smoking at least once a week. Almost half of the participants (47.7\%) reported smoking more than 10 cigarettes per day.

\section{Quit/smoking reduction rates}

No significant increase in smoking abstinence was documented at the 1 month and 6 months follow- 
Table 6. Proportion of adolescents self-reporting abstinence or smoking reduction at the 1 month and at the 6 months follow-up assessment

\begin{tabular}{|c|c|c|c|c|}
\hline & $\begin{array}{l}\text { Al } 1 \mathrm{n} \\
\text { follor } \\
\text { assess }\end{array}$ & $\begin{array}{l}\text { onth } \\
\text { upent }\end{array}$ & $\begin{array}{l}\text { M } 6 \text { 11 } \\
\text { follo } \\
\text { asses: }\end{array}$ & $\begin{array}{l}\text { onths } \\
\text { ment }\end{array}$ \\
\hline & n & $\%$ & n & $\%$ \\
\hline Abstinent/participants reached & $0 / 56$ & 0 & $1 / 39$ & 2.6 \\
\hline $\begin{array}{l}\text { Abstinent/participants reached } \\
\text { with missing data replaced }{ }^{a}\end{array}$ & $0 / 65$ & 0 & $1 / 65$ & 1.5 \\
\hline $\begin{array}{l}\text { Reduction of } \geq 50 \% \text { in CPD/ } \\
\text { participants reached }\end{array}$ & $30 / 48$ & 62.5 & $9 / 39$ & 23.1 \\
\hline $\begin{array}{l}\text { Reduction of } \geq 50 \% \text { in CPD/ } \\
\text { participants reached with missing } \\
\text { data replaced }^{\text {a }}\end{array}$ & $30 / 65$ & 46.2 & $9 / 65$ & 13.8 \\
\hline $\begin{array}{l}\text { Reduction in } \mathrm{CPD}^{\mathrm{b}} / \text { participants } \\
\text { reached }\end{array}$ & $38 / 48$ & 79.2 & $19 / 39$ & 48.7 \\
\hline $\begin{array}{l}\text { Reduction in CPD/participants } \\
\text { reached with missing data } \\
\text { replaced }^{\text {a }}\end{array}$ & $38 / 65$ & 58.5 & $19 / 65$ & 29.2 \\
\hline
\end{tabular}

up (Table 6). Sixty-three per cent of participants reported a $50 \%$ or greater reduction in cigarettes smoked per day at the 1 month follow-up (Table 6). This decreased to $23.1 \%$ of the participants at the 6 months follow-up. Similar trends were noted for a reduction of 2 or more CPD. Much of the observed decrease in smoking reduction at the 6 months follow-up was due to losses between the follow-up at 1 month and at 6 months.

\section{DISCUSSION}

This pilot study examined the real-world performance of the 2017 TOBg Guidelines ${ }^{8}$ addressing tobacco cessation for adolescents. The TOBg Guidelines identified school-based interventions as being among the most promising approaches for influencing tobacco use among adolescents and, therefore, the present study focussed on the school setting. Specifically, the study: 1) exposed a group of prevention practitioners who work with schools in Greece to the TOBg Guideline recommendations for adolescent smoking cessation, 2) trained them on a school-based intervention that drew on the recommendations, and 3) tested its influence on the smoking behavior of the participants.

Practitioners exposed to the TOBg Guidelines reported high rates of satisfaction with their use and most of them considered that the guidelines will inform the preparation of future interventions targeting tobacco use prevention and cessation among adolescents. There were some mixed reactions among practitioners in terms of the degree to which the guidelines provided new information. Furthermore, our study did not document any significant changes in the level of practitioners' knowledge following their exposure to the guidelines. The latter may be due to the already high rates of knowledge among the practitioners who participated in the study, given that they were all experienced prevention professionals working in Prevention Centres. Our pilot study found that practitioners' self-efficacy in delivering tobacco treatment to adolescents who smoke increased significantly following exposure to the TOBg Guidelines and training. Given that self-efficacy has been found elsewhere to be highly correlated to rates of tobacco treatment delivery among health care providers ${ }^{12,13}$, this finding could be considered as an important outcome of our pilot intervention and an important target for increasing intervention rates $^{18,19}$

The 3-session group-based intervention tested in schools was associated with a reduction in cigarettes smoked per day among adolescent participants, although no significant effect on smoking abstinence was observed. These findings are consistent with those reported in other studies, which have shown that school-based interventions, if well designed, can be effective in reducing short-term abstinence and reducing daily cigarette consumption; however the effectiveness on long-term smoking abstinence remains unclear ${ }^{7,8,15}$. While the primary study outcome was complete abstinence from smoking, it should be noted that reducing tobacco consumption may increase the chance of quitting in the future. The school-based intervention was counsellingbased and nicotine replacement treatments were not provided to students. Our student sample reported fairly high rates of nicotine dependence and as such it is possible that the addition of nicotine replacement therapy may have increased cessation rates.

Besides elements pertaining to the study design, it would be important to note that the effectiveness 
of tobacco cessation interventions that target adolescents may depend on numerous factors, ranging from intra-personal characteristics (e.g. level of nicotine dependence, skills, knowledge, attitudes, etc.), to inter-personal (e.g. parental and peer influences), community (e.g. availability of tobacco selling points or of screening and smoking cessation services), and public policy influences (e.g. prices of tobacco products, law enforcement, etc. $)^{8,19,20}$. The present study did not take into account the smoking culture (e.g. prevalence, rules, teachers who smoked, etc.) in the schools where the interventions took place, which may have impacted on the outcome of the intervention as a whole. Also, our study took place in Greece where the prevalence of tobacco use in the general population is among the highest in Europe ${ }^{21}$, with selling prices of cigarettes lower than in many other EU countries ${ }^{22}$, and where policies such as smoke-free areas or restrictions of cigarette sales to minors are poorly enforced $^{23,24}$

Both the content and length of intervention appear to be important predictors of successful smoking cessation outcomes in adolescent samples, with higher cessation rates found for programs involving motivational enhancement and lasting for at least five sessions ${ }^{10,25}$. Consistent with the data, practitioners involved in the present study reported concerns that while the intervention was feasible, the period allowed for the delivery of the schoolbased cessation intervention was not sufficient, as the intervention was delivered towards the end of the school year when the high-school students begin to focus on their final exams. In all schools, practitioners were able to complete only 3 groupbased sessions with the adolescents, prior to the summer holidays, and this was in their opinion a factor that hindered the impact of the intervention. Moreover, the proximity of the implementation period to the final school exams and summer vacations was potentially an additional limiting factor in achieving higher recruitment and cessation rates. Future interventions should be planned to start early in the school year, so that the necessary optimum duration for the intervention can be ensured.

\section{Limitations}

The study findings should be interpreted in the light of several additional limitations. These include the relatively small sample size and the use of a non-randomized design. The small sample size of the prevention practitioners may have masked improvements in the knowledge base of the participants following exposure to the Guidelines. The lack of a control group means that we are unable to confirm any causal relationship between the intervention and changes in smoking outcomes, and it is possible that some participants would have quit smoking without the support of the current intervention. Two of the 18 prevention practitioners involved in the study were current smokers at the time of the intervention, thus their personal smoking status may have had a negative impact on the effectiveness of their intervention in schools. Given that these were a minority of practitioners, and that they were delivering a standardized curriculum, the overall effect on our study findings is expected not to be large. Furthermore, a significant number of students, who initially expressed interest in participating in the groupbased cessation program, declined the opportunity to enrol, citing concerns about parental consent. While only $15 \%$ of data were missing among adolescents sampled at the 1 month follow-up, this increased to $40 \%$ at the 6 months follow-up. The follow up at 6 months occurred during the summer vacations (August-September), which may have been an additional obstacle to reaching students. Future programs should be designed to minimize this barrier to participation.

\section{CONCLUSIONS}

Despite limitations, the present study showed that the TOBg Guidelines were received with satisfaction among prevention practitioners working with adolescents and increased practitioners' self-efficacy for delivering evidencebased programs targeting adolescent tobacco users. Although our study did not document an effect on smoking abstinence among the majority of adolescents, it adds to the existing evidence regarding the effects of school-based smoking cessation interventions that draw on cognitive behavioural and motivational enhancement strategies, and the potential of such interventions to reduce daily tobacco consumption in a real- 
world setting. Further studies, with larger samples, are needed to confirm the effects observed in this pilot study based on the TOBg Guidelines.

\section{REFERENCES}

1. The ESPAD Group. ESPAD Report 2015. Results from the European School Survey Project on Alcohol and other Drugs. Luxembourg: Publications Office of the European Union;2016.

2. Palmer R, Young S, Hopfer C, et al. Developmental epidemiology of drug use and abuse in adolescence and young adulthood: Evidence of generalized risk. Drug Alcohol Depend. 2009;102(1):78-87. doi:10.1016/j.drugalcdep.2009.01.012

3. Sims TH. The Committee on Substance Abuse. Technical Report-Tobacco as a substance of abuse. Pediatrics. 2009;124(5):e1045-1053. doi:10.1542/peds.2009-2121

4. Fidler J, Wardle J, Brodersen NH, Jarvis M, West R. Vulnerability to smoking after trying a single cigarette can lie dormant for three years or more. Tob. Control. 2006;15(3):205-209. doi:10.1136/tc.2005.014894

5. Williams PG, Holmbeck GN, Greenley RN. Adolescent health psychology. J. Consult. Clin. Psychol. 2002;70(3):828-842. doi:10.1037//0022-006x.70.3.828

6. Pbert L, Moolchan ET, Muramoto M, et al. The state of office-based interventions for youth tobacco use. Pediatrics. 2003;111(6):e650-e660. doi:10.1542/peds.111.6.e650

7. Fanshawe T, Halliwell W, Lindson N, Aveyard P, Livingstone-Banks J, Hartmann-Boyce J. Tobacco cessation interventions for young people. . Cochrane Database of Systematic Reviews 2017;11(Art. No.: CD003289). doi: 10.1002/14651858

8. Fotiou A, Stavrou M, Kokkevi A. Smoking Cessation among Adolescents. In: Behrakis PK, Vardavas CI, Papadakis S, eds. Tobacco Cessation Guidelines for High Risk Groups (TOB.g). Athens: European Network for Smoking Prevention; 2017.

9. Grimshaw GM, Stanton A. Tobacco cessation interventions for young people. Cochrane Database Syst Rev. 2006(4):CD003289. doi:10.1002/14651858.cd003289.pub4

10. Sussman S, Sun P, Dent CW. A meta-analysis of teen cigarette smoking cessation. Health Psychol. 2006;25(5):549. doi:10.1037/0278-6133.25.5.549

11. Thomas RE, McLellan J, Perera R. Effectiveness of school-based smoking prevention curricula: systematic review and meta-analysis. BMJ Open. 2015;5(3):e006976. 10.1136/bmjopen-2014-006976

12. Behrakis P, Vardavas C, Papadakis S, eds. Tobacco Cessation guidelines for High-risk Populations (TOB.g). Athens, Greece: European Network for Smoking Prevention; 2017.

13. Girvalaki C, Papadakis S, Vardavas CI, Pipe A, Lionis
C. Tobacco treatment TrAining Network in Crete (TiTAN-Crete): protocol for a controlled before-after study. Tobacco Prevention \& Cessation. 2016;2(June). doi:10.18332/tpc/63823

14. Papadakis S, Pipe AL, Reid RD, et al. Effectiveness of performance coaching for enhancing rates of smoking cessation treatment delivery by primary care providers: Study protocol for a cluster randomized controlled trial. Contemporary clinical trials. 2015;45:184-190. doi:10.1016/j.cct.2015.08.013

15. Ampt AJ, Amoroso C, Harris MF, McKenzie SH, Rose VK, Taggart JR. Attitudes, norms and controls influencing lifestyle risk factor management in general practice. BMC Family Practice. 2009;10(1):59. doi:10.1186/1471-2296-10-59

16. Delucchi KL, Tajima B, Guydish J. Development of the smoking knowledge, attitudes, and practices (S-KAP) instrument. Journal of drug issues. 2009;39(2):347-363. doi:10.1177/002204260903900207

17. West R, Hajek P, Stead L, Stapleton J. Outcome criteria in smoking cessation trials: proposal for a common standard. Addiction. Mar 2005;100(3):299-303. doi:10.1111/j.1360-0443.2004.00995.x

18. Schnoll RA, Rukstalis M, Wileyto EP, Shields AE. Smoking cessation treatment by primary care physicians: an update and call for training. Am. J. Prev. Med. 2006;31(3):233239. doi:10.1016/j.amepre.2006.05.001

19. O’Loughlin J, Makni H, Tremblay M, et al. Smoking cessation counseling practices of general practitioners in Montreal. Prev. Med. 2001;33(6):627-638. doi:10.1006/pmed.2001.0937

20. King JL, Merten JW, Wong T-J, Pomeranz JL. Applying a social-ecological framework to factors related to nicotine replacement therapy for adolescent smoking cessation. Am. J. Health Promot. 2017;32(5):12911303. doi:10.1177/0890117117718422

21. Filippidis FT, Vardavas CI, Loukopoulou A, Behrakis P, Connolly GN, Tountas Y. Prevalence and determinants of tobacco use among adults in Greece: 4 year trends. European Journal of Public Health. 2013;23(5):772776. doi:10.1093/eurpub/cks148

22. Eurostat. Comparative price levels for food, beverages and tobacco. Eurostat statistics explained 2017; http:// ec.europa.eu/eurostat/statistics-explained/index.php/ Comparative_price_levels_for_food,_beverages_and_ tobacco. Accessed 7 June 2018, 2018.

23. Ferketich AK, Lugo A, La Vecchia C, et al. Relation between national-level tobacco control policies and individual-level voluntary home smoking bans in Europe. Tob. Control. 2016;25(1):60-65. doi:10.1136/tobaccocontrol-2014-051819

24. Faculty of the Harvard School of Public Health. The Greek Tobacco Epidemic: Center for Global Tobacco Control; Department of Society, Human Development and Health; Harvard School of Public Health; 2011. 
25. Sussman S, Sun P. Youth tobacco use cessation: 2008 update. Tobacco Induced Diseases. 2009;5(1):3-3. doi: 10.1186/1617-9625-5-3

\section{ACKNOWLEDGEMENTS}

We would like to acknowledge the support of the Greek Organization Against Drugs, especially the collaboration of the following Prevention Centres and practitioners (names in brackets): ANELIXIS Tripoli (I. Sideri); ATHINA-ERGANI (D. Loizou); ATHINA-PALLAS (I. Nezis); Alimou, Argyroupolis, Glyfadas, Ellinikou (M. Charatsidou; E. Karantana); DIKTIO ALFA Thessaloniki (F. Maroglou); ELPIDA Thessaloniki (V. Asketopoulou); ODIPORIKO Peristeri (L. Efstathiou; K. Stavropoulou); ORAMA Edessa (C. Tramposinis); PRONOI Kifisia (V. Alexaki); PYXIDA Thessaloniki; SCHEDIA loannina (V. Basoyianni); SIRIOS Thessaloniki (N. Zachartzi; A. Chatzintai). Special thanks to Ms. Ioulia Bafi, head of prevention at the Greek National Monitoring \& Documentation Center for Drugs, for her support in the implementation of the pilot project.

\section{CONFLICTS OF INTEREST}

P. K. Behrakis is the Editor of TPC and there are no conflicts of interest with the current work. The rest of the authors also have completed and submitted an ICMJE form for disclosure of potential conflicts of interest. The authors declare that they have no competing interests, financial or otherwise, related to the current work.

\section{FUNDING}

This study was funded from the European Union's Health Programme 2014-2020 (Project ID\# 664292).

PROVENANCE AND PEER REVIEW Not commissioned; externally peer reviewed. 